\title{
The Influence of Gaze Control on Visual Perception: Eye Movements and Visual Stability
}

\author{
RebecCA M. Krock ${ }^{1}$ AND Tirin Moore ${ }^{1,2}$ \\ ${ }^{1}$ Department of Neurobiology, Stanford University School of Medicine, Stanford, California 94305 \\ ${ }^{2}$ Howard Hughes Medical Institute, Stanford University School of Medicine, Stanford, \\ California 94305 \\ Correspondence: tirin@stanford.edu
}

\begin{abstract}
Primates make several saccadic eye movements each second, and yet the retinal motion these movements generate goes unnoticed. Saccadic suppression is a profound loss of visual sensitivity occurring around the time of eye movements, and it is thought to contribute to visual stability by blunting the perception of self-generated motion. Neurophysiological studies have produced evidence that neurons throughout the visual system, including both the dorsal and ventral streams of extrastriate visual cortex, show a reduction in visual responses or sensitivity around the time of saccades. However, the source of this suppression remains unknown. We review evidence that oculomotor regions such as the superior colliculus and frontal eye field may play a role, as well as anatomical data that place constraints on possible mechanisms of suppression.
\end{abstract}

In spite of the constant shifting of our gaze from one stimulus to another, we perceive the visual world to be a stable and continuous whole (Fig. 1A,B). By comparison, a quick displacement of an eye with one's finger results in a marked perception of visual motion. This difference suggests the existence of some form of active mechanism that contributes to perceived stability during centrally generated eye movements. Although substantial progress has been made in understanding the neural mechanisms of visual processing during passive fixation, saccadic eye movements (saccades) punctuate these fixations approximately two to four times each second during free viewing. The mechanisms by which the brain compensates for the visual disruption that eye movements introduce remain largely unknown. A recent body of evidence implicates the saccadic system in the modulation of visual cortical representations and of perception (e.g., Moore 2006; Squire et al. 2013), but large gaps remain in our understanding of the neural circuitry that could specifically underlie the illusion of stability during eye movements.

One psychophysical phenomenon thought to reflect an active mechanism in perceived stability during eye movements is saccadic suppression. Saccadic suppression is a profound loss of visual sensitivity that takes place around the time of saccadic eye movements (Fig. 1C). For example, when human observers are asked to report the presence or absence of a visual probe appearing just before, during, or after a saccade, their contrast detection thresholds show an approximately fivefold elevation above those measured when the probe occurs during fixation (Latour 1962; Zuber and Stark 1966; Bridgeman et al. 1975; Burr et al. 1982, 1994; Shioiri and Cavanagh 1989; Diamond et al. 2000; Knöll et al. 2011). Saccadic suppression has also been reported in nonhuman primates, both during the fast (saccadic) phase of optokinetic nystagmus (Mohler and Cechner 1975), as well as during microsaccades (Hass and Horwitz 2011).

Given the frequency at which primates make saccadic eye movements, these findings imply that primate vision is impaired much of the time. The benefit conferred by a reduction of self-generated visual motion during saccades evidently outweighs the disadvantages of frequent visual impairment. Consistent with this, some patients with cerebellar or brainstem lesions experience visual motion in conjunction with abnormal spontaneous eye movements that they report to be disabling and distressing (Corkill and Vijayan 1976; Tilikete and Vighetto 2011). Suppression of vision during saccades therefore appears to play a critical role in perceptual stability across saccades. Here, we review (1) psychophysical studies exploring possible mechanisms of saccadic suppression, (2) neural correlates in the primate visual system, (3) anatomical data that constrain possible mechanisms of saccadic suppression, and (4) functional evidence that the saccadic system plays a role in modulating perisaccadic visual representations in the visual system.

\section{PSYCHOPHYSICAL EVIDENCE FOR A CENTRAL SOURCE OF SUPPRESSION}

Psychophysical studies have examined two basic classes of potential mechanisms for saccadic suppression. Active mechanisms for suppression would likely incorporate some form of a centrally generated (extraretinal) signal coupled to the motor command to move the eyes, known as corollary discharge or efference copy. It has 
A

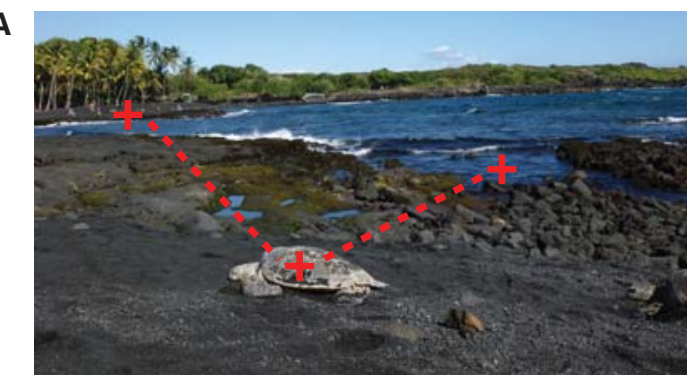

B

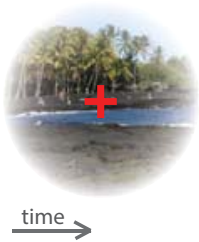

C

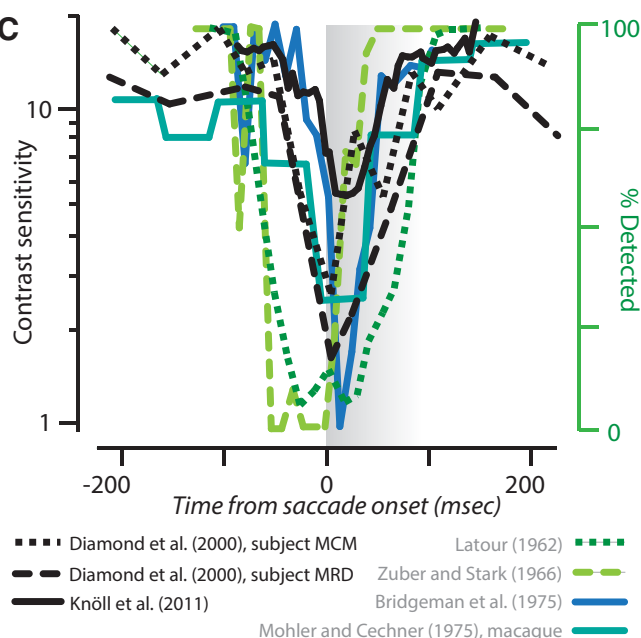

Figure 1. (A) Primates make frequent saccades to inspect features of the visual world (crosses, points of fixation; dashed lines, saccade vectors). $(B)$ Between successive fixations (red crosses), no visual motion is perceived. Instead, visual perception consists of a series of stable snapshots. $(C)$ A selection of psychophysical studies demonstrating that around the time of eye movements, contrast sensitivity (black $y$-axis) and the likelihood of detecting a visual stimulus (green $y$-axis) decline sharply.

long been argued that an active mechanism must be at play (Holt 1903; von Helmholtz 1925; Sperry 1950; von Holst and Mittelstaedt 1950). Passive mechanisms are those that would depend solely on visual feedback (reafference) generated by the saccade. These could include an inability of neurons early in the visual system to resolve high-speed visual stimuli and/or visual masking, in which the ability to perceive one visual stimulus is compromised by the appearance of another stimulus close by in space and time. Active and passive mechanisms are not mutually exclusive, and support has been found for both.

If passive mechanisms are responsible for saccadic suppression, then moving a visual stimulus across the eye at the high speeds achieved by saccades should reduce its visibility compared with stable stimulus. (Saccades shift the direction of gaze $>100^{\circ}$ of visual angle per second; $1^{\circ}$ of visual angle is approximately the width of one's thumb held at arm's length.) Consistent with this, Dorr and Bex (2013) found that moving naturalistic stimuli across the eyes generated a saccadic suppression-like effect. Other studies, however, have found variable effects depending on the image features. Burr and Ross (1982) observed that although humans can resolve lowspatial-frequency sine-wave gratings moving at saccadic speeds, psychophysical contrast detection thresholds for moving, high-spatial-frequency gratings are in fact elevated, especially at lower illumination levels. These data suggest that passive mechanisms may specifically play a role in reducing the visibility of high-frequency, low-luminance stimuli during saccades. Yet sensitivity to low spatial frequencies moving at saccadic speeds is maintained and even enhanced for the lowest spatial frequencies, and it is at low spatial frequencies (below $\sim 0.3$ cycles/dva) that saccadic suppression is strongest (Burr et al. 1982). Thus, an active mechanism seems necessary to explain saccadic suppression of at least the low-spatialfrequency content of images.
Diamond et al. (2000) addressed the relative roles of passive and active mechanisms by comparing visual sensitivity when subjects made saccades over an image (the "active" condition) and when the image was moved over their eyes during fixation (the "passive" condition). When this image included high-contrast noise, they found that passive visual motion was sufficient to generate a suppressive effect equal to that observed in the active condition. However, when the image consisted solely of a horizontal sinusoidal grating that was swept horizontally across the eyes, such that there was little visual motion, suppression was observed in the "active" condition but not in the "passive" condition. Thus, saccadic suppression persisted even when passive mechanisms were excluded. This evidence is consistent with the idea that passive mechanisms may be sufficient to explain saccadic suppression under some visual conditions, but an active mechanism or mechanisms are also at play.

\section{SACCADIC SUPPRESSION OF NEURONAL RESPONSES TO VISUAL STIMULI}

Neural correlates of saccadic suppression have been observed in the responses of neurons throughout the primate visual system, including the lateral geniculate nucleus (LGN), the superior colliculus (SC), the pulvinar nucleus, primary visual cortex (V1), and extrastriate areas V2, V3, V4, MT, LIP, and VIP (Table 1; Fig. 2). Many of these studies have used strategies to minimize visual reafference and isolate any active mechanisms of saccadic suppression, such as presenting stimuli just before or after eye movements while the eye is still stable (e.g., Ibbotson et al. 2008; Bremmer et al. 2009; Han et al. 2009; Berman and Wurtz 2011), using spatially uniform stimuli (e.g., Mohler and Cechner 1975; Reppas et al. 2002; Sylvester et al. 2005), and/or comparing responses to active and 
Table 1. Summary of past studies of neural correlates of saccadic suppression in humans and nonhuman primates

\begin{tabular}{|c|c|c|c|c|c|c|}
\hline Year & Authors & Region & $\begin{array}{c}\text { Saccadic } \\
\text { suppression }\end{array}$ & $\begin{array}{l}\text { \% Suppression } \\
\text { (max across time) }\end{array}$ & $\begin{array}{l}\text { \% Cells suppressed } \\
\text { (if applicable) }\end{array}$ & $\begin{array}{l}\text { Posts accadic } \\
\text { enhancement }\end{array}$ \\
\hline 1975 & Mohler and Cechner & V1 & $\checkmark$ & [] & {[]} & \\
\hline 1976 & $\begin{array}{l}\text { Bartlett, Doty, Lee, and } \\
\text { Sakakura }\end{array}$ & $\begin{array}{l}\text { Geniculostriate } \\
\text { tract }\end{array}$ & $\checkmark$ & $\begin{array}{r}43 \% \text { (Magnocellular) } \\
17 \% \text { (parvocellular) }\end{array}$ & $\checkmark$ & \\
\hline 1976 & Robinson and Wurtz & $\mathrm{SC}$ & $\checkmark$ & [] & $61 \%$ & \\
\hline \multirow[t]{2}{*}{1991} & Robinson, McClurkin, & $\mathrm{SC}$ & $\checkmark$ & [] & $75 \%$ & \\
\hline & Kertzman, and Petersen & $\mathrm{Pi} / \mathrm{Pl}$ & $\checkmark$ & [] & $45 \%$ & \\
\hline 2001 & $\begin{array}{l}\text { Ramcharan, Gnadt, and } \\
\text { Sherman }\end{array}$ & LGN & & & $\checkmark$ & \\
\hline 2011 & Hass and Horwitz & V1 & $\checkmark$ & $17 \%$ & [] & $\checkmark$ \\
\hline 2002 & Reppas, Usrey, and Reid & LGN & $\checkmark$ & $20 \%$ & $\begin{array}{r}90 \% \text { (Magnocellular) } \\
21 \% \text { (parvocellular) }\end{array}$ & $\checkmark$ \\
\hline \multirow[t]{3}{*}{2002} & Thiele, Henning, & MST & $\checkmark$ & [] & $68.1 \%$ & \\
\hline & Kubischik, and Hoffman & MT & $\checkmark$ & [] & $66 \%$ & \\
\hline & & $\begin{array}{l}\text { V1/V2 (Human) } \\
\text { V3 (Human) }\end{array}$ & $\checkmark$ & $24 \%$ & & \\
\hline \multirow[t]{6}{*}{2004} & Kleiser, Seitz, and & V4 (Human) & $\checkmark$ & $50 \%$ & & \\
\hline & Krekelberg & hMT+ (Human) & $\checkmark$ & $34 \%$ & & \\
\hline & & V7 (Human) & $\checkmark$ & $46 \%$ & & \\
\hline & & IPS (Human) & $\checkmark$ & $14 \%$ & & \\
\hline & & LGN (Human) & $\checkmark$ & {[]} & & \\
\hline & & V1 (Human) & $\checkmark$ & [] & & \\
\hline \multirow[t]{4}{*}{2005} & $\begin{array}{l}\text { Sylvester, Haynes, and } \\
\text { Rees }\end{array}$ & V2 (Human) & & & & \\
\hline & & V3 (Human) & & & & \\
\hline & & MT (Human) & & & & \\
\hline & & LGN (Human) & $\checkmark$ & [] & & \\
\hline \multirow[t]{3}{*}{2006} & Sylvester and Rees & V1 (Human) & $\checkmark$ & [] & & \\
\hline & & V2 (Human) & & & & \\
\hline & & V3 (Human) & $\checkmark$ & [] & & \\
\hline 2007 & $\begin{array}{l}\text { Ibbotson, Price, Crowder, } \\
\text { Ono, and Mustari }\end{array}$ & $\mathrm{MT} / \mathrm{MST}$ & $\checkmark$ & [] & $83 \%$ & $\checkmark$ \\
\hline 2008 & $\begin{array}{l}\text { Ibbotson, Crow der, } \\
\text { Cloherty, Price, and } \\
\text { Mustari }\end{array}$ & MSTd & $\checkmark$ & $81 \%$ & [] & $\checkmark$ \\
\hline \multirow[t]{2}{*}{2008} & $\begin{array}{l}\text { Kagan, Gur, and } \\
\text { Snodderly }\end{array}$ & V1 & $\checkmark$ & [] & [] & $\checkmark$ \\
\hline & & MT & $\checkmark$ & $26 \%$ & [] & $\checkmark$ \\
\hline \multirow[t]{3}{*}{2009} & $\begin{array}{l}\text { Bremmer, Kubischik, } \\
\text { Hoffmann, and }\end{array}$ & MST & $\checkmark$ & $19 \%$ & [] & $\checkmark$ \\
\hline & & VIP & $\checkmark$ & $20 \%$ & [] & $\checkmark$ \\
\hline & & LIP & $\sqrt{ }$ & $22 \%$ & {[]} & $\times$ \\
\hline 2009 & Han, Xian, and Moore & V4 & $\checkmark$ & $\begin{array}{l}43 \% \text { (decrease in } \\
\text { contrast sensitivity) }\end{array}$ & $42.6 \%$ & \\
\hline 2010 & $\begin{array}{l}\text { Cloherty, Mustari, Rosa, } \\
\text { and Ibbotson }\end{array}$ & MSTd & $\sqrt{ }$ & $80 \%$ & $79 \%$ & $\checkmark$ \\
\hline 2010 & Hafed and Krauzlis & $\mathrm{SC}$ & $\checkmark$ & $30 \%$ & [] & $x$ \\
\hline 2011 & Berman and Wurtz & $\mathrm{P}$ & $\checkmark$ & [] & $24 \%$ & \\
\hline
\end{tabular}

Although paradigmatic differences make precise comparison between studies impossible, the strength of suppression is estimated here by the percent reduction in visual responses across all cells, at the time of deepest suppression with respect to the saccade (column five) and/or the percent of cells suppressed (column six). A number of studies report postsaccadic enhancement, usually following perisaccadic suppression, in the LGN, V1, MT, MST, and VIP (column seven).

[], exact value not reported; entry left blank if not applicable.

passive visual motion (e.g., Robinson and Wurtz 1976; Reppas et al. 2002; Thiele et al. 2002; Ibbotson et al. 2007). Correlates of saccadic suppression are consistently observed under all of these conditions, supporting a role for an active, extraretinal mechanism of suppression.

In addition to these neural correlates, saccadic suppression of perception has also been observed in the macaque. Mohler and Cechner (1975) showed that macaques' ability to detect briefly flashed stimuli is impaired by $0.5-0.8$ log units during the fast (saccadic) phase of optokinetic nystagmus. Similarly to human saccadic suppression, this impairment stretches from $\sim 50 \mathrm{msec}$ before to $50 \mathrm{msec}$ after eye movement initiation and is accompanied by a loss of visual responses in striate cortex. More recently, Hafed and Krauzlis (2010) observed perimicrosaccadic suppression of visual bursts in the SC accompanied by elevation of saccadic reaction times. Finally, Hass and Horwitz (2011) found that the occurrence of microsaccades during stimulus presentation impaired detection of achromatic stimuli.

Saccadic suppression occurs for luminance-modulated stimuli, but not equiluminant chromatic stimuli (Burr 
Pathways for perisaccadic modulation of visual cortex

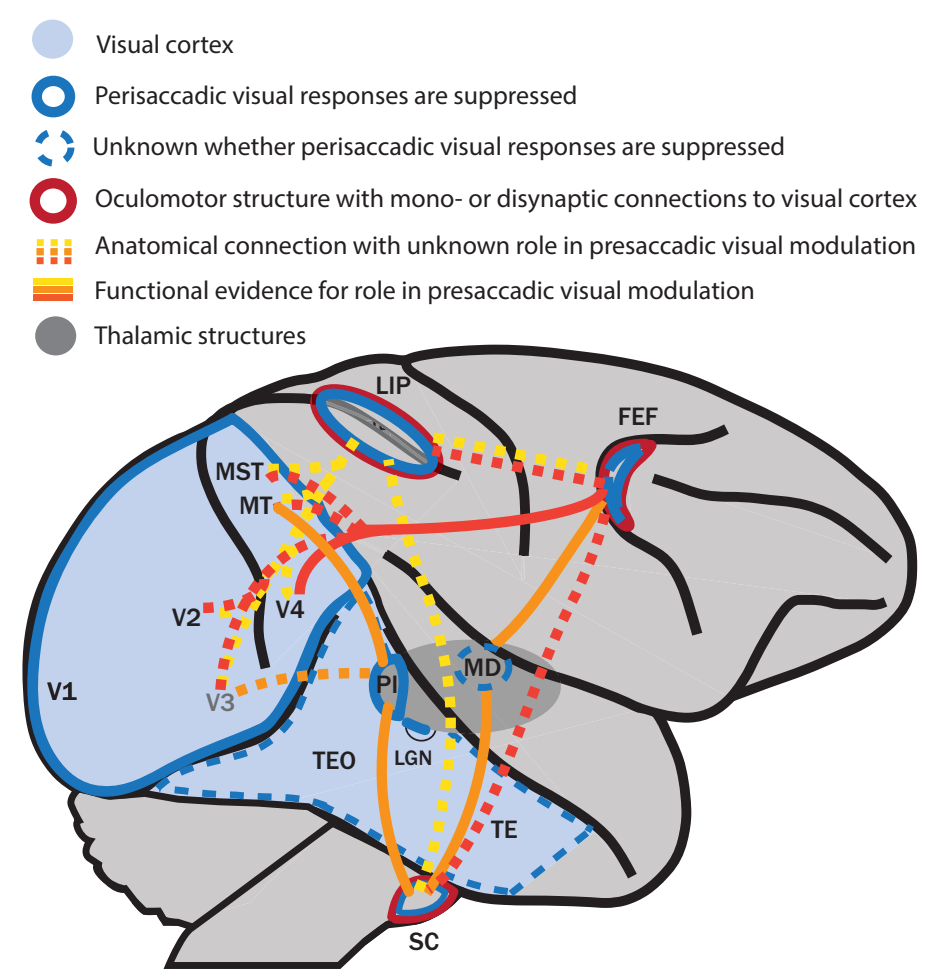

Figure 2. Summary of mono- and disynaptic pathways between oculomotor areas and visual cortex. Saccadic suppression (blue outlines) is observed in both the dorsal and ventral streams of visual cortex (Kleiser et al. 2004; Bremmer et al. 2009; Han et al. 2009) as well as in oculomotor structures including LIP (Bremmer et al. 2009), the superior colliculus (Robinson and Wurtz 1976; Hafed and Krauzlis 2010), and the frontal eye field (Krock and Moore, abstract in Society for Neuroscience 2014). The superior colliculus sends disynaptic projections (medium orange lines) to dorsal stream but not ventral stream visual areas (Lyon et al. 2010), whereas the FEF (red-orange lines) and LIP (yellow lines) are reciprocally connected with both ventral and dorsal visual cortex (Baizer et al. 1991; Shipp and Zeki 1995; Stanton et al. 1995; Ungerleider et al. 2008; Anderson et al. 2011). Extensive connectivity also exists between these oculomotor regions, including a corollary discharge pathway from the SC to FEF (Sommer and Wurtz 2000, 2002, 2006; Ferraina et al. 2002; Berman et al. 2009). FEF, frontal eye field; LIP, lateral intraparietal area; SC, superior colliculus; PI, inferior pulvinar; LGN, lateral geniculate nucleus; MD, mediodorsal thalamus; MST, medial superior temporal; MT, middle temporal.

et al. 1994). Evidence for maintenance of chromatic contrast sensitivity during saccades was also found in macaques (Hass and Horwitz 2011). This observation has prompted a number of experiments exploring the hypothesis that saccadic suppression first occurs in the color-insensitive magnocellular pathway of the LGN, sparing representations of color in the parvocellular and koniocellular layers. In support of this argument, suppression may be more common in magnocellular neurons than parvocellular neurons. However, identical patterns of suppression beginning $\sim 100 \mathrm{msec}$ before saccades are present in magnocellular, parvocellular, and koniocellular LGN cells (Reppas et al. 2002; Royal et al. 2006). Furthermore, neuronal firing rate responses and blood-oxygen-level-dependent (BOLD) responses to both chromatic and achromatic stimuli appear similarly suppressed in human LGN and V1 (Kleiser et al. 2004; Sylvester and Rees 2006; Hass and Horwitz 2011). These studies also show that saccadic suppression in the LGN is followed by much stronger postsaccadic enhancement, a pattern that is not observed in psychophysical measurements (Burr et al. 1994; Diamond et al. 2000; Knöll et al. 2011) or in downstream visual areas (Bremmer et al. 2009).

Another potential explanation for the luminance selectivity of saccadic suppression could be that suppression is biased toward the relatively color-insensitive dorsal stream, though neurophysiological evidence does not unequivocally support this view. Visual responses are suppressed in dorsal areas V3, MT, and MST (Thiele et al. 2002; Kleiser et al. 2004; Ibbotson et al. 2007; Bremmer et al. 2009; Cloherty et al. 2010). However, strong luminance-selective suppression is present in the ventral stream as well (Kleiser et al. 2004). Han et al. (2009) measured V4 neuronal contrast sensitivity using a staircasing procedure to determine the threshold contrast that elicited a significant response from each neuron (Fig. 3). They found a 0.5 log-unit decrease in sensitivity to brief, luminance-contrast modulated presaccadic visual probes. In contrast to the LGN and V1, perisaccadic sensitivity to red-green modulated equiluminant stimuli was less reduced in V4, paralleling human perception. Although the luminance specificity of saccadic suppression may yet be an important clue to its neural implementa- 
A

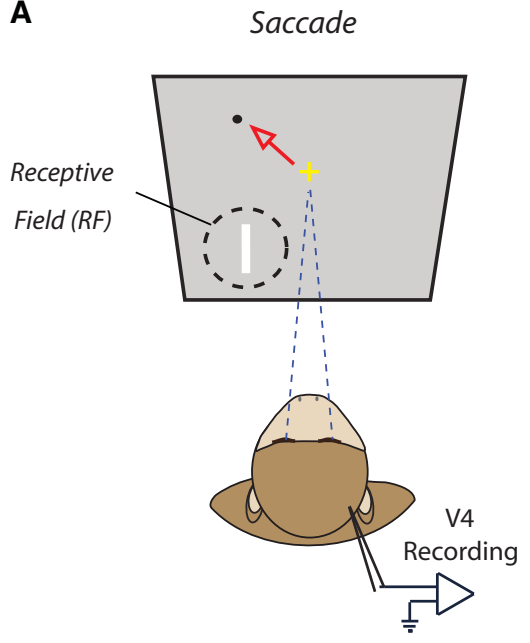

B
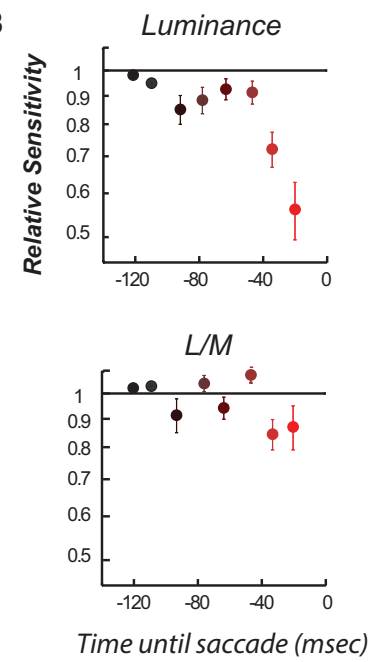

Figure 3. Saccadic suppression of luminance contrast sensitivity of V4 neurons. $(A)$ The monkey was cued to make a visually guided saccade (red arrow, planned saccade vector; yellow cross, eye position.) A brief visual probe consisting of an oriented bar was presented inside the V4 receptive field at varying times with respect to the saccade onset. Luminance or chromatic contrast of the probe was varied across trials in a staircase procedure to determine the threshold contrast that elicited a neuronal response. $(B)$ For luminance-contrast modulated probes, neuronal sensitivity declined by $50 \%$ just before movement onset. There was minimal change to neuronal sensitivity to red-green equiluminant modulated stimuli. (Modified from Han et al. 2009.)

tion, the existing data on the subject leave many questions unanswered.

\section{ANATOMIC CONSTRAINTS ON POSSIBLE MECHANISMS OF SUPPRESSION}

Although psychophysical and neurophysiological studies support a role for an active suppressive mechanism in saccadic suppression, exactly what form this mechanism might take is unclear. One type of mechanism that is frequently postulated to play a role is corollary discharge, defined as a copy of a motor signal that is used to alter sensory representations. A structure that could produce a corollary discharge would need to have information about impending saccades, implicating particular oculomotor structures. To date, the clearest evidence of a saccadic corollary discharge pathway involves the indirect pathway from the SC to the FEF. Sommer and Wurtz (2008) identified a pathway from the SC to the frontal eye field via the mediodorsal thalamus that appears necessary both for accurate behavioral updating of eye position (Sommer and Wurtz 2002) and for modulating eye movement signals within the FEF (Sommer and Wurtz 2006).

In addition, one might expect corollary discharge signals to directly convey information about impending saccades to the visual system to alter visual representations (Wurtz et al. 2011). Indeed, a simple implementation of a corollary discharge might consist of an inhibitory signal that originates in an oculomotor structure and suppresses visual representations. Yet because long-range cortical connections are overwhelmingly excitatory, it is unlikely that any saccade command signal directly inhibits neurons in visual cortex. For example, $\sim 90 \%$ of the projections of FEF neurons to extrastriate area V4 terminate directly onto the dendritic spines of pyramidal cells, precluding the possibility that FEF neurons directly inhibit neurons in this area (Anderson et al. 2011). Another way that oculomotor structures could contribute to perisaccadic insensitivity of visual cortex is via a decrease in excitatory modulation. Berman and Wurtz (2010) used orthodromic and antidromic stimulation to identify a disynaptic relay from the superior colliculus to area MT via the inferior pulvinar. These pulvinar relay cells showed a robust suppression of activity around the time of saccades (Berman and Wurtz 2011). These data are consistent with the idea that the SC contributes to saccadic suppression of visual representations in MT via a reduction of excitation. In addition, recent evidence indicates that SC projection through the pulvinar and into extrastriate visual cortex is exclusively projected to areas of the dorsal visual stream (e.g., MT) and not to ventral stream areas (e.g., V4) (Berman and Wurtz 2010; Lyon et al. 2010). This suggests a possible basis for the relative sparing of chromatic and high spatial frequency vision during saccadic suppression (Burr et al. 1994; Han et al. 2009).

If the SC indeed transmits suppressed visual responses to visual cortex during saccades, where might suppression within the superior colliculus originate? The avian optic tectum (OT), a homolog of the primate SC, is part of a circuit that generates global competitive suppression and sharpens selection of saccade target representations (Mysore and Knudsen 2013; Goddard et al. 2014). The intermediate and deep layer neurons of the OT send topographic projections to the isthmi pars magnocellularis (Imc), the avian homolog of the lateral tegmental nucleus, which in turn sends global inhibitory projections back to the OT. The global inhibition mediated by the Imc is powerful even at great distances from the chosen target 
representation. This network could generate global suppression of visual responses within the OT around the time of eye movements. In the future, it will be of interest to determine whether activity in the intermediate and deep layers of the primate SC is necessary for saccadic suppression of visual responses in the superficial and intermediate SC, in visual cortex, and for saccadic suppression measured behaviorally.

\section{MODULATION OF VISUAL CORTICAL SIGNALS BY THE FEF}

It is now evident that the visually driven responses of neurons within posterior visual cortex are significantly influenced by the activity of neurons within the FEF (for review, see Squire et al. 2013). Of particular importance are the observations that changes in FEF neuronal activity are sufficient to alter the gain of stimulus-driven responses in extrastriate visual cortex (Moore and Armstrong 2003; Armstrong et al. 2006; Ekstrom et al. 2009; Noudoost and Moore 2011a). The FEF is directly connected to neurons within extrastriate visual cortex, including extrastriate areas MT and V4 (Fig. 2; Stanton et al. 1995). The influence of FEF neurons on posterior visual cortex appears to be accomplished, at least in part, via direct excitatory connections from FEF neurons onto pyramidal neurons within retinotopically corresponding columns within extrastriate cortex (e.g., area V4) (Anderson et al. 2011). One current view posits that saccaderelated activity within the FEF neurons participates in a recurrent excitatory circuit that can simultaneously amplify visual responses at prospective saccadic target locations and further specify the precise saccade vector needed to foveate particular visual targets (Moore et al. 2003; Schafer and Moore 2007; Hamker et al. 2008; Noudoost and Moore 2011b). In the proposed circuit, the recurrent excitatory interactions between the FEF and extrastriate cortex also facilitates competitive, local inhibitory interactions between cortical columns representing different locations in space, resulting in progressively greater gain disparities between target and nontarget locations (Hamker et al. 2008; Noudoost and Moore 2011b). Such a circuit is consistent with the observation that stimulation of FEF sites both facilitates the visually driven responses at retinotopically corresponding locations and suppresses the responses at noncorresponding locations (Fig. 4; Moore and Armstrong 2003). It is also consistent with the observation that visual receptive fields within visual cortex (Tolias et al. 2001) and within the FEF (Zirnsak et al. 2014) appear to converge toward the location of impending saccadic targets (Hamker et al. 2008). In addition, the proposed circuit also seems consistent with basic phenomenon of saccadic suppression in that it predicts a reduction in visual processing and sensitivity at all locations outside of the target location during saccadic eye movements. Indeed, both the psychophysical and the physiological data to date indicate that around the time of saccades, visual sensitivity at the target location is increased in exchange for large decrements in sensitivity elsewhere (Zirnsak and Moore 2014).

\section{CONCLUDING REMARKS}

We have reviewed evidence that although numerous psychophysical and neurophysiological studies have showed a role for an active suppressive mechanism in
A

Subthreshold microstimulation

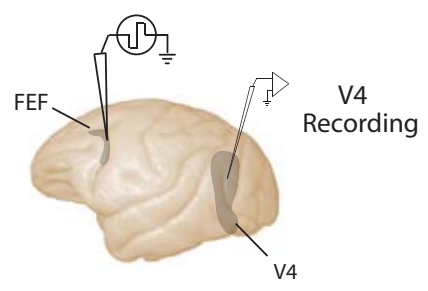

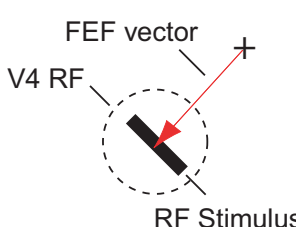

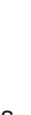

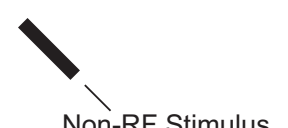

B

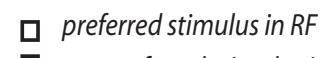

- nonpreferred stimulus in $R F$

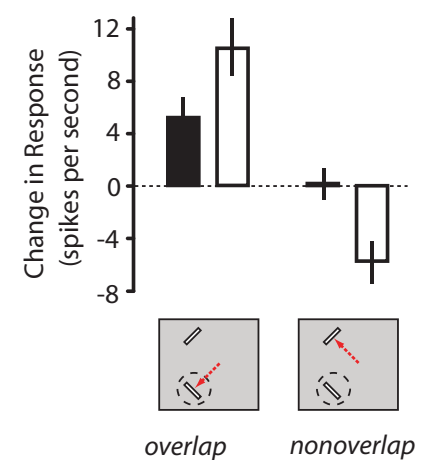

Figure 4. Modulation of visually driven responses of area V4 neurons with microstimulation of the FEF. ( $A$ ) Sites within the FEF were electrically stimulated while recording from neurons in area V4. Cartoon shows a side view of the macaque brain. (Top) The locations of the FEF in the anterior bank of the arcuate sulcus and of area V4 in the prelunate gyrus and below the inferior occipital sulcus are shown (both shaded). Monkeys performed a fixation task while oriented bar stimuli were presented inside the recorded V4 neuron's receptive field (RF) (dotted circle) and at another location outside the RF. The stimulation and recording sites in the FEF and area V4, respectively, could be chosen such that the FEF saccade vector (arrow) and the area V4 neuron's RF overlapped spatially. ( $B$ ) The stimulation and recording sites in the FEF and area V4, respectively, could be chosen for each experiment such that the FEF saccade vector (dotted red arrow) and the area V4 neuron's RF (dotted circle) were either spatially overlapping (left) or nonoverlapping (right). In the overlapping configuration, FEF stimulation enhanced the V4 neuron's response to visual stimuli appearing in the RF, and these enhancements mirrored the modulations observed during covert spatial attention in that more enhancement was seen for preferred than nonpreferred stimuli (left). In contrast, in the nonoverlapping configuration no response enhancement was produced. 
saccadic suppression, many questions remain about the precise form this mechanism might take. Neural correlates of saccadic suppression have been observed throughout the visual and saccadic systems, but these data leave open the question of what the source(s) of this suppression could be. Although corollary discharge seems to be a likely mechanism, direct inhibition of visual cortex by oculomotor structures is unlikely; instead, structures such as the FEF and SC could contribute to saccadic suppression of visual cortical representations through a loss of excitatory feedback. Future studies are needed to determine whether the SC, the FEF, or other structures in the saccadic system play a causal role in the generation of saccadic suppression of neural visual representations and psychophysical contrast sensitivity.

\section{REFERENCES}

Anderson JC, Kennedy H, Martin KA. 2011. Pathways of attention: Synaptic relationships of frontal eye field to V4, lateral intraparietal cortex, and area 46 in macaque monkey. J Neurosci 31: 10872-10881.

Armstrong KM, Fitzgerald JK, Moore T. 2006. Changes in visual receptive fields with microstimulation of frontal cortex. Neuron 50: 791-798.

Baizer JS, Ungerleider LG, Desimone R. 1991. Organization of visual inputs to the inferior temporal and posterior parietal cortex in macaques. J Neurosci 11: 168-190.

Berman RA, Wurtz RH. 2010. Functional identification of a pulvinar path from superior colliculus to cortical area MT. $J$ Neurosci 30: 6342-6354.

Berman RA, Wurtz RH. 2011. Signals conveyed in the pulvinar pathway from superior colliculus to cortical area MT. J Neurosci 31: 373-384.

Berman RA, Joiner WM, Cavanaugh J, Wurtz RH. 2009. Modulation of presaccadic activity in the frontal eye field by the superior colliculus. J Neurophysiol 101: 2934-2942.

Bremmer F, Kubischik M, Hoffman KP, Krekelberg B. 2009. Neural dynamics of saccadic suppression. J Neurosci 29: $12374-12383$

Bridgeman B, Hendry D, Stark L. 1975. Failure to detect displacement of the visual world during saccadic eye movements. Vision Res 15: 719-722.

Burr DC, Ross J. 1982. Contrast sensitivity at high velocities. Vision Res 22: 479-484.

Burr DC, Holt J, Johnston JR, Ross J. 1982. Selective depression of motion sensitivity during saccades. J Physiol 333: 1-15.

Burr DC, Morrone MC, Ross J. 1994. Selective suppression of the magnocellular visual pathway during saccadic eye movements. Nature 371: 511-513.

Cloherty SL, Mustari MJ, Rosa MG, Ibbotson MR. 2010. Effects of saccades on visual processing in primate MSTd. Vision Res 50: $2683-2691$.

Corkill G, Vijayan N. 1976. Saccadic visual suppression and down-beat nystagmus: A case of Arnold-Chiari malformation. Surg Neurol 5: 95-96.

Diamond MR, Ross J, Morrone MC. 2000. Extraretinal control of saccadic suppression. J Neurosci 20: 3449-3455.

Dorr M, Bex PJ. 2013. Peri-saccadic natural vision. J Neurosci 33: $1211-1217$.

Ekstrom LB, Roelfsema PR, Arsenault JT, Kolster H, Vanduffel W. 2009. Modulation of the contrast response function by electrical microstimulation of the macaque frontal eye field. J Neurosci 29: 10683-10694.

Ferraina S, Paré M, Wurtz RH. 2002. Comparison of corticocortical and cortico-collicular signals for the generation of saccadic eye movements. J Neurophysiol 87: 845-858.

Goddard CA, Mysore SP, Bryant AS, Huguenard JR, Knudsen EI. 2014. Spatially reciprocal inhibition of inhibition within a stimulus selection network in the avian midbrain. PLoS One 9: e85865.

Hafed ZM, Krauzlis RJ. 2010. Microsaccadic suppression of visual bursts in the primate superior colliculus. J Neurosci 30: $9542-9547$.

Hamker FH, Zirnsak M, Calow D, Lappe M. 2008. The perisaccadic perception of objects and space. PLoS Comput Biol 4: e31.

Han X, Xian SX, Moore T. 2009. Dynamic sensitivity of area V4 neurons during saccade preparation. Proc Natl Acad Sci 106: 13046-13051.

Hass CA, Horwitz GD. 2011. Effects of microsaccades on contrast detection and V1 responses in macaques. $J$ Vis 11: $1-17$.

Holt E. 1903. Eye movement and central anaesthesia. Harvard Psychol Stud 1: 3-45.

Ibbotson MR, Price NS, Crowder NA, Ono S, Mustari MJ. 2007. Enhanced motion sensitivity follows saccadic suppression in the superior temporal sulcus of the macaque cortex. Cereb Cortex 17: 1129-1138.

Ibbotson MR, Crowder NA, Cloherty SL, Price NS, Mustari MJ. 2008. Saccadic modulation of neural responses: Possible roles in saccadic suppression, enhancement, and time compression. J Neurosci 28: 10952-10960.

Kleiser R, Seitz RJ, Krekelberg B. 2004. Neural correlates of saccadic suppression in humans. Curr Biol 14: 386-390.

Knöll J, Binda P, Morrone MC, Bremmer F. 2011. Spatiotemporal profile of peri-saccadic contrast sensitivity. J Vis 11: 1-12.

Latour PL. 1962. Visual threshold during eye movements. $\mathrm{Vi}$ sion Res 2: 261-262.

Lyon DC, Nassi JJ, Callaway EM. 2010. A disynaptic relay from superior colliculus to dorsal stream visual cortex in macaque monkey. Neuron 65: 270-279.

Mohler CW, Cechner R. 1975. Saccadic suppression in the monkey. Vision Res 15: 1157-1160.

Moore T. 2006. The neurobiology of visual attention: Finding sources. Curr Opin Neurobiol 16: 159-165.

Moore T, Armstrong KM. 2003. Selective gating of visual signals by microstimulation of frontal cortex. Nature 421: $370-$ 373.

Moore T, Armstrong KM, Fallah M. 2003. Visuomotor origins of covert spatial attention. Neuron 40: 671-683.

Mysore SP, Knudsen EI. 2013. A shared inhibitory circuit for both exogenous and endogenous control of stimulus selection. Nat Neurosci 16: 473-478.

Noudoost B, Moore T. 2011a. Control of visual cortical signals by prefrontal dopamine. Nature 474: 372-375.

Noudoost B, Moore T. 2011b. The role of neuromodulators in selective attention. Trends Cogn Sci 15: 585-591.

Ramcharan EJ, Gnadt JW, Sherman SM. 2001. The effects of saccadic eye movements on the activity of geniculate relay neurons in the monkey. Vis Neurosci 18: 253-258.

Reppas JB, Usrey WM, Reid RC. 2002. Saccadic eye movements modulate visual responses in the lateral geniculate nucleus. Neuron 35: 961-974.

Robinson DL, Wurtz RH. 1976. Use of an extraretinal signal by monkey superior colliculus neurons to distinguish real from self-induced stimulus movement. J Neurophysiol 39: 852 870.

Robinson DL, McClurkin JW, Kertzman C, Petersen SE. 1991. Visual responses of pulvinar and collicular neurons during eye movements of awake, trained macaques. J Neurophysiol 66: $485-496$.

Royal DW, Sáry G, Schall JD, Casagrande VA. 2006. Correlates of motor planning and postsaccadic fixation in the macaque monkey lateral geniculate nucleus. Exp Brain Res 168: 62-75.

Schafer RJ, Moore T. 2007. Attention governs action in the primate frontal eye field. Neuron 56: 541-551.

Shioiri S, Cavanagh P. 1989. Saccadic suppression of low-level motion. Vision Res 29: 915-928.

Shipp S, Zeki S. 1995. Segregation and convergence of specialized pathways in macaque monkey visual cortex. $J$ Anat 187: 547-562. 


\section{KROCK AND MOORE}

Sommer MA, Wurtz RH. 2000. Composition and topographic organization of signals sent from the frontal eye field to the superior colliculus. J Neurophysiol 83: 1979-2001.

Sommer MA, Wurtz RH. 2002. A pathway in primate brain for internal monitoring of movements. Science 296: 1480-1482.

Sommer MA, Wurtz RH. 2006. Influence of the thalamus on spatial visual processing in frontal cortex. Nature 444: $374-$ 377.

Sommer MA, Wurtz RH. 2008. Brain circuits for the internal monitoring of movements. Annu Rev Neurosci 31: 317-338.

Sperry RW. 1950. Neural basis of the spontaneous optokinetic response produced by visual inversion. J Comp Physiol Psychol 43: 482-489.

Squire RF, Noudoost B, Schafer RJ, Moore T. 2013. Prefrontal contributions to visual selective attention. Annu Rev Neurosci 36: $451-466$.

Stanton GB, Bruce CJ, Goldberg ME. 1995. Topography of projections to posterior cortical areas from the macaque frontal eye fields. J Comp Neurol 353: 291-305.

Sylvester R, Rees G. 2006. Extraretinal saccadic signals in human LGN and early retinotopic cortex. NeuroImage 30: 214 219.

Sylvester R, Haynes JD, Rees G. 2005. Saccades differentially modulate human LGN and V1 responses in the presence and absence of visual stimulation. Curr Biol 15: 37-41.

Thiele A, Henning P, Kubischik M, Hoffman KP. 2002. Neural mechanisms of saccadic suppression. Science 295: 24602462.
Tilikete C, Vighetto A. 2011. Oscillopsia: Causes and management. Curr Opin Neurol 24: 38-43.

Tolias AS, Moore T, Smirnakis SM, Tehovnik EJ, Siapas AG, Schiller PH. 2001. Eye movements modulate visual receptive fields of V4 neurons. Neuron 29: $757-$ 767.

Ungerleider LG, Galkin TW, Desimone R, Gattass R. 2008. Cortical connections of area V4 in the macaque. Cereb Cortex 18: $477-499$.

von Helmholtz H. 1925. Physiological optics (ed. Southall J), Vol. III. Banta, Menasha, WI.

von Holst E, Mittelstaedt H. 1950. The reafference principle. Interaction between the central nervous system and the periphery. In Selected papers of Erich von Holst: The behavioural physiology of animals and man, Vol. 1:1, pp. 39-73. Methuen, London.

Wurtz RH, Joiner WM, Berman RA. 2011. Neuronal mechanisms for visual stability: Progress and problems. Philos Trans $R$ Soc Lond B Biol Sci 366: 492-503.

Zirnsak M, Moore T. 2014. Saccades and shifting receptive fields: Anticipating consequences or selecting targets? Trends Cogn Sci 18: 621-628.

Zirnsak M, Steinmetz NA, Noudoost B, Xu KZ, Moore T. 2014. Visual space is compressed in prefrontal cortex before eye movements. Nature 507: 504-507.

Zuber BL, Stark L. 1966. Saccadic suppression: Elevation of visual threshold associated with saccadic eye movements. Exp Neurol 16: 65-79. 


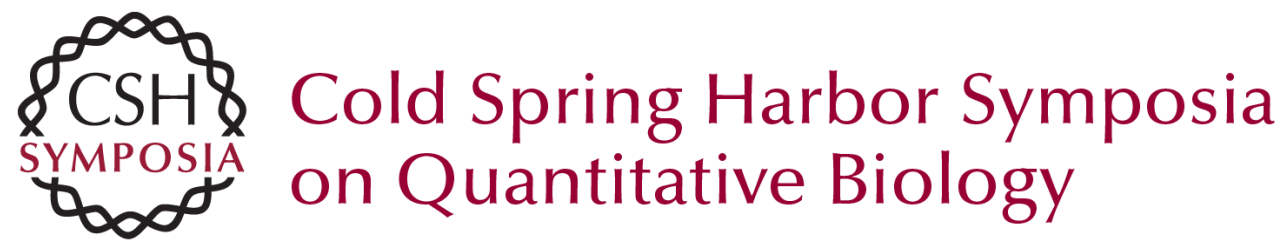

\section{The Influence of Gaze Control on Visual Perception: Eye Movements and Visual Stability}

Rebecca M. Krock and Tirin Moore

Cold Spring Harb Symp Quant Biol 2014 79: 123-130 originally published online March 9, 2015 Access the most recent version at doi:10.1101/sqb.2014.79.024836

References This article cites 62 articles, 15 of which can be accessed free at: http://symposium.cshlp.org/content/79/123.full.html\#ref-list-1

License

Email Alerting Receive free email alerts when new articles cite this article - sign up in Service the box at the top right corner of the article or click here. 